\title{
TERMITICIDAL ACTIVITY OF Toona sinensis WOOD VINEGAR AGAINST Coptotermes curvignathus Holmgren
}

\author{
Morina Adfa $^{1}{ }^{*}$, Arif J. Kusnanda ${ }^{1}$, Wendra D. Saputra ${ }^{1}$, Charles Banon ${ }^{1}$, \\ Mai Efdi' ${ }^{2}$, and Mamoru Koketsu ${ }^{3,4}$ \\ ${ }^{1}$ Department of Chemistry, Faculty of Mathematics and Natural Sciences, University of \\ Bengkulu, Jalan W.R. Supratman, Bengkulu 38371, Indonesia \\ ${ }^{2}$ Department of Chemistry, Faculty of Mathematics and Natural Sciences, Andalas \\ University, 25163 Limau Manis, Padang, Indonesia \\ ${ }^{3}$ Department of Chemistry and Biomolecular Sciences, Faculty of Engineering, Gifu \\ University, 1-1 Yanagido, Gifu 501-1193, Japan \\ ${ }^{4}$ Department of Materials Science and Technology, Faculty of Engineering, Gifu University, \\ 1-1 Yanagido, Gifu 501-1193, Japan \\ *E-mail: morinaadfa@unib.ac.id; morinaadfa@yahoo.com
}

\begin{abstract}
Termiticidal activity of wood vinegar from Toona sinensis (TS) sawdust has been evaluated against Coptotermes curvignathus. TS wood vinegar was produced at $250-300^{\circ} \mathrm{C}$ pyrolysis temperature, and a no-choice test was applied for evaluating termiticidal activity with thirty-three active termites. The concentrations of TS wood vinegar in the dried filter paper was prepared to $0 \%$ (solvent only), $2 \%, 4 \%, 6 \%$, and $8 \%$. The TS wood vinegar showed strong termiticidal activity and that concentrations of wood vinegar significantly influenced mortality of termite. The termite mortality increased when the concentration of wood vinegar increased, at a concentration of $8 \%$ all termites dead after 3 days tested. Forty constituents were characteristic on the basis of GC-MS data, and 33 components were identified. The organic compounds in TS wood vinegar were classified into carboxylic acids, phenols, ketones, amides, aldehydes, furans, esters, alcohols, sugar derivative, and ether, and among of this components, acetic acid comprised 57.43\%. The contents of organic fraction of TS wood vinegar and largely acetic acid might be responsible for the termiticidal activity. Base on physicochemical properties, TS wood vinegar has a good quality as well.
\end{abstract}

Keywords: Toona sinensis, wood vinegar, termiticidal activity, GC-MS

() RASĀYAN. All rights reserved

\section{INTRODUCTION}

Termite is recognized as insect pest in the human institution, agriculture, and forestry crop. Reducing the use of persistent organic insecticide has led to a search for effective, environmentally friendly compounds with anti-termite activities. The genus Coptotermes is found in tropical and subtropical regions of the world and is the most devastating genus pest insects in Asia and Australia ${ }^{1}$. Scientists in different parts of the world are working for the development and establishment biopesticides or natural pesticides. Biopesticides are natural plant products that have many activities such as insecticidal activity $^{2,3}$, suppress the growth of fungal ${ }^{4}$, repellent to pests ${ }^{5}$, a deterrent to feeding ${ }^{6}$, insect growth regulation, and toxicity to agricultural pests ${ }^{7}$.

Wood vinegar which is also called as pyroligneous acid or liquid smoke is a product by processing of high-temperature carbonization of wood with absent of oxygen. Wood vinegar contains $10-20 \%$ organic compounds including more than 200 chemical components with mainly acetic acid. It also contains various kinds of phenol, carbonyl, and alcohol. In pesticide application, wood vinegar has been widely used as a wood preservative, fungicide, repellent and insecticide, herbicide, and feed-stuff ${ }^{8}$. Yatagai et al. ${ }^{9}$ was reported that wood vinegar produced from mixed chips of Cryptomeria japonica and 
Pseudotsuga menziesii; Quercus serrata; and Pinus densiflora exhibited high termiticidal activity against Reticulitermes speratus.

Suren (Toona sinensis) timbers are the most popular used in the furniture and construction in West Sumatera region caused by durability, beauty, and its color. Therefore sawdust waste can be found every day at the furniture factories or wood workshops. Previously, we reported termiticidal activity of stem wood and stem bark methanol extracts of $T$. sinensis and its isolated compounds with moderate activity ${ }^{2}$. To continue our study concerning the potential of $T$. sinensis from Indonesia as biopesticides, in this study we evaluated the termiticidal activity of $T$. sinensis wood vinegar against Coptotermes curvignathus and its chemical components.

\section{Materials}

\section{EXPERIMENTAL}

Sawdust of Toona sinensis was collected from Kanagarian Sungai Jernih, Kecamatan Gunung Talang, Kabupaten Solok, West Sumatera-Indonesia and then air dried in Laboratory of Organic Chemistry, Department of Chemistry, University of Bengkulu. Chemicals $(\mathrm{NaOH}$, oxalic acid anhydrous, and phenolphthalein) were purchased from Sigma-Aldrich.

\section{Instrumentation}

GC-MS data were measured with Agilent Series (Agilent Technologies Inc., GC Seri 6980 and MS Seri 5973). A $60 \mathrm{~m}$ capillary column HP-5MS (Agilent 1909S1S-436) with id $0.25 \mathrm{~mm}$ and $0.25 \mu \mathrm{m}$ film thickness was used and maximal column temperature is $350^{\circ} \mathrm{C}$. The carrier gas was helium. Front inlet mode: split with initial temperature $280^{\circ} \mathrm{C}$ and split flow $199.6 \mathrm{~mL} / \mathrm{min}$. The mass spectrometer was operated in electron-ionization (EI) mode at $70 \mathrm{eV}$. The mass spectra were obtained by Acquisition mode scan of the mass range from 40 to 500 .

\section{Procedure}

\section{Preparation of Wood Vinegar from Toona sinensis}

Wood vinegar was produced from burning sawdust of Suren wood (Toona sinensis) (300 g) in a pyrolysis reactor at $250-300^{\circ} \mathrm{C}$ temperatures. This process was repeated three times and the vinegar was combined. The collected wood vinegar was stored at room temperature and sedimentation for 3 months to separate $\operatorname{tar}^{10}$. The wood vinegar was weighed to calculate the yield, color and odor were observed as well.

\section{Physicochemical Properties of Wood Vinegar}

The $\mathrm{pH}$ value of wood vinegar was measured by a $\mathrm{pH}$ meter (HANNA HI-98107). Organic acid was determined by the method of acid-base titration with $0.001 \mathrm{~N} \mathrm{NaOH}$ and expressed as acetic acid (\%). The density of wood vinegar was measured by the pycnometer ${ }^{11}$.

\section{Analysis of Wood Vinegar by GC-MS}

The analysis of chemical components of Toona sinensis (TS) wood vinegar was carried out using GCMS. The compounds were identified based on the comparison of their retention time (RT) and mass spectra of Wiley, NIST library data of the GC-MS system. The percentage of components was calculated by the GC peak area

\section{Termiticidal Activity of Wood Vinegar}

Workers and soldiers of Coptotermes curvignathus Holmgren were collected from trees were attacked by termites around the University of Bengkulu and identified at School of biological sciences and technology, Institute Technology Bandung, Indonesia. The colony was maintained at $28^{\circ} \mathrm{C} \pm 2$ and $80 \%$ $\pm 5 \mathrm{RH}$ in a glass container, until used. The termites were fed wet filter paper during storage in the laboratory. A no-choice test was employed for evaluating the termiticidal activity of TS wood vinegar according to the previous method ${ }^{2}$. The concentrations of TS wood vinegar in the dried filter paper was 
prepared to $0 \%$ (solvent only), 2\%, 4\%, 6\% and $8 \% \%$ (sample mass $(\mathrm{mg}) /$ filter paper mass $(\mathrm{mg}) \times$ $100 \%$ ), and was applied to filter papers (Whatman No. 3, diameter $90 \mathrm{~mm}$ ) after dissolved in $500 \mu \mathrm{L}$ methanol. Thirty-three active termites (30 workers and 3 soldiers) from the adult of Coptotermes curvignathus were added to Petri dishes ( $90 \mathrm{~mm}$ in dia $\times 20 \mathrm{~mm}$ height) and kept in a dark room at room temperature $\left(28^{\circ} \mathrm{C} \pm 2\right)$ for 1 week. Filter paper treated with methanol only was used as the control. The number of dead termites was counted daily and the five replications were performed for each concentration. The termicidal activity was evaluated from the termite mortality (\%) average, and the $\mathrm{LC}_{50}$ after three days exposures was calculated with Probit analysis ${ }^{12}$.

\section{Statistical Analysis}

Duncan's multiple comparison tests were used to evaluate differences in percent mortality of termites. Results with $P<0.05$ were considered significant. Calculations were performed using statistical software SPSS 16.0 according to the previous report ${ }^{13}$.

\section{RESULTS AND DISCUSSION}

\section{Yield, Physicochemical Properties, and Chemical Components of Toona sinensis Wood Vinegar}

The yield of TS wood vinegar was $20.29 \%$, with reddish brown in color, smoky in odor, and transparent. The total organic acids contain $10.897 \%$, the $\mathrm{pH}$ value was 3.25 , and density was $1.058 \mathrm{~g} / \mathrm{cm}^{3}$. Wada ${ }^{14}$ has been suggested the criteria for good quality of the wood vinegar such as: $\mathrm{pH}$ around 3; specific gravity around 1.010-1.050 g.mL-1; color (visually) pale yellow, bright brown or reddish brown; smoky odor; and transparency visually is transparent with no suspended matter. On the other hand, Mathew and Zakaria ${ }^{15}$ have been review physicochemical characteristics of pyroligneous acid produced from different plant sources (Rubber wood, Birch heartwood, Wallnut tree branches, Moso bamboo, Walnut shell, Mixed chips of Quercus sp, and Coconut shell) with variation carbonization temperature where wood vinegar exhibited the $\mathrm{pH}$ value $1.8-3.8$, and density $1.009-1.09 \mathrm{~g} / \mathrm{cm}^{3}$. Thereby, the TS wood vinegar in current study appeared to be of good quality in terms of color, odor, $\mathrm{pH}$, density, and transparency because of the value as in accordance with the previous report. The quality of wood vinegar depending on the type of starting materials, pyrolysis time and temperature pyrolysis ${ }^{16}$.

The composition of wood vinegar was characterized by 40 components (Figure-1), and 33 components were identified. The identified components are listed in Table-1 belong to 10 groups. The GC-MS indicated that TS wood vinegar were mainly contain carboxylic acids (61.96\%, 6 components), phenols (8.29\%, 9 components), ketones (4.75\%, 4 components), amides (4.43\%, 2 components), aldehydes (3.58\%, 3 components), and a few furans ( $2.7 \%, 2$ components), esters (2.6\%, 2 components), alcohols (1.98\%, 3 components), sugar derivative $(1.29 \%, 1$ component), and ether ( $0.56 \%, 1$ component), successively. The result showed that organic acids were the major components of TS wood vinegar, while acetic acid was the largest component (57.43\%) among 6 kinds of organic acids. Following organic acids, phenols were the primary compounds in TS wood vinegar, among them 2,6dimethoxyphenol/ syringol $(2.41 \%)$ was identified as the major phenol compound. Phenols basically result from the thermal degradation of $\operatorname{lignin}^{17}$. Similarly to Akakabe et al. ${ }^{18}$ perhaps acetic acid, and syringol were contributed to the characteristic odor of TS wood vinegar. That result was agreement with Zhai et al. ${ }^{10}$ that reported were organic acids, phenolic compounds, ketones, aldehydes, and benzene and its derivatives were the major components obtained at the middle temperature (190 to $\left.290^{\circ} \mathrm{C}\right)$ pyrolysis range. Thermal cracking of wood is degradation of hemicellulose, cellulose, and lignin ${ }^{19}$. The acetic acid is believed to have originated from the acetyl groups in the hemicellulose ${ }^{20}$ and was the largest content of the wood vinegar samples obtained in the current study.

\section{Anti-termite activity of Toona sinensis wood vinegar}

We evaluated the termiticidal activity of TS wood vinegar at various concentrations with no choice test. The mortality of termite after exposure with TS wood vinegar and their statistical analysis was shown in Table-2. TS wood vinegar exhibited strong termiticidal activity, the termite mortality increased when the concentration of wood vinegar increased. At a concentration of $2 \%$ all termites dead after 7 days 
RASĀYAN J. Chem.

tested, after the concentration increased to $4 \%, 6 \%$, and $8 \%$ all termite dead after 6,5 , and 3 days, successively. The mortality of termite increased significantly after 3 days, with its $\mathrm{LC}_{50}$ of $2.94 \%$. The termiticidal activity of TS wood vinegar may due to its components. Acetic acid (57.43\%) which contain more than 50\% in TS wood vinegar, propionic acid (3.27\%), and syringol (2.41\%) might be largely contributed to termiticidal activity in addition to other minor components. The results are agreement with Yatagai et al. ${ }^{9}$ that acetic acid is the largest content of wood vinegar made from mixed chips of Cryptomeria japonica and Pseudotsuga menziesii; Quercus serrata; and Pinus densiflora exhibited high termiticidal activity against $R$. speratus, and phenol with some substituents revealed higher termiticidal activity than benzene derivatives, which have no hydroxyl group, an ortho substituent of phenol plays an important role in termiticidal activity. On the other hand, filtrates from biomass slurry fuel/wood vinegar from sugi and acacia wood had no important termiticidal activity against $C$. formosanus. Though high acetic and lactic acids content of the wood vinegar, the presence of vanillin in sugi and acacia wood vinegar may have served as an additional food source and promoted termite $\operatorname{attack}^{20}$.

Table-1: Identified chemical components of Toona sinensis wood vinegar

\begin{tabular}{c|l|c}
\hline RT (min) & Compounds & $\begin{array}{c}\text { Peak area } \\
(\%)\end{array}$ \\
\hline 3.879 & 3,4-Furandiol, tetrahydro, cis & 1.04 \\
\hline 3.932 & Methyl glyoxal & 0.94 \\
\hline 4.191 & Acetic acid & 57.43 \\
\hline 4.414 & Propionic acid & 3.27 \\
\hline 4.557 & 1,3-Butanediol & 0.59 \\
\hline 4.843 & Ethanimidic acid, ethyl ester & 0.87 \\
\hline 4.896 & 2-Oxo, butanoic acid & 0.24 \\
\hline 4.965 & Succindialdehyde & 0.65 \\
\hline 5.033 & 2,4-Dimethyloxetane & 0.56 \\
\hline 5.197 & 3-Methylbutanoid acid & 0.20 \\
\hline 5.346 & 2,5-Dimethylfuran & 1.08 \\
\hline 5.399 & 2-Methyl-propanoic acid/ isobutyric acid & 0.25 \\
\hline 5.494 & 2-Methyl-propanal/ Isobutyraldehyde & 1.99 \\
\hline 5.939 & 1-Pentanol, 4-amino & 0.35 \\
\hline 6.029 & Butyrolactone & 1.73 \\
\hline 6.527 & Phenol & 0.45 \\
\hline 6.802 & 1-Hydroxy-2-pentanone & 1.70 \\
\hline 7.083 & 3-Methylcyclopentane-1,2-dione & 2.21 \\
\hline 7.204 & 2,3-Dimethyl-2-cyclopenten-1-one & 0.17 \\
\hline 7.432 & 2-Methyltetrahydrofuran & 1.62 \\
\hline 7.686 & 2-Methoxyphenol/ Guaiacol & 1.68 \\
\hline 7.808 & N,N-Dimetylacetamide & 3.89 \\
\hline 7.988 & 4-Ethylcyclohexanone & 0.67 \\
\hline 8.698 & 2-Methoxy-4-methylphenol/ Creosol & 0.78 \\
\hline 8.751 & 2-Hydroxyphenol/ Catechol & 0.67 \\
\hline 8.793 & Cyclopropanecarboxylic acid & 0.57 \\
\hline 8.920 & 1,4:3,6-Dianhydro-,, ,-d-glucopyranose & 1.29 \\
\hline 9.518 & 4-Ethyl-2-methoxyphenol/ 4-Ethylguaiacol & 0.18 \\
\hline 10.170 & 2,6-Dimethoxyphenol/ Syringol & 2.41 \\
\hline 10.996 & 3,5-Dimethoxy-4-hydroxytuluen & 1.05 \\
\hline 11.652 & 2,6-Dihydroxy-4-methoxyacetophenone & 0.72 \\
\hline 11.795 & 4-(2-Hydroxyethyl)-2-methoxyphenol & 0.35 \\
\hline 11.907 & N-Acetylpropanamide & 0.54 \\
\hline & & \\
\hline
\end{tabular}


RASĀYAN J. Chem.

Vol. 10 | No. 4 |1088-1093 | October - December | 2017

Abundance

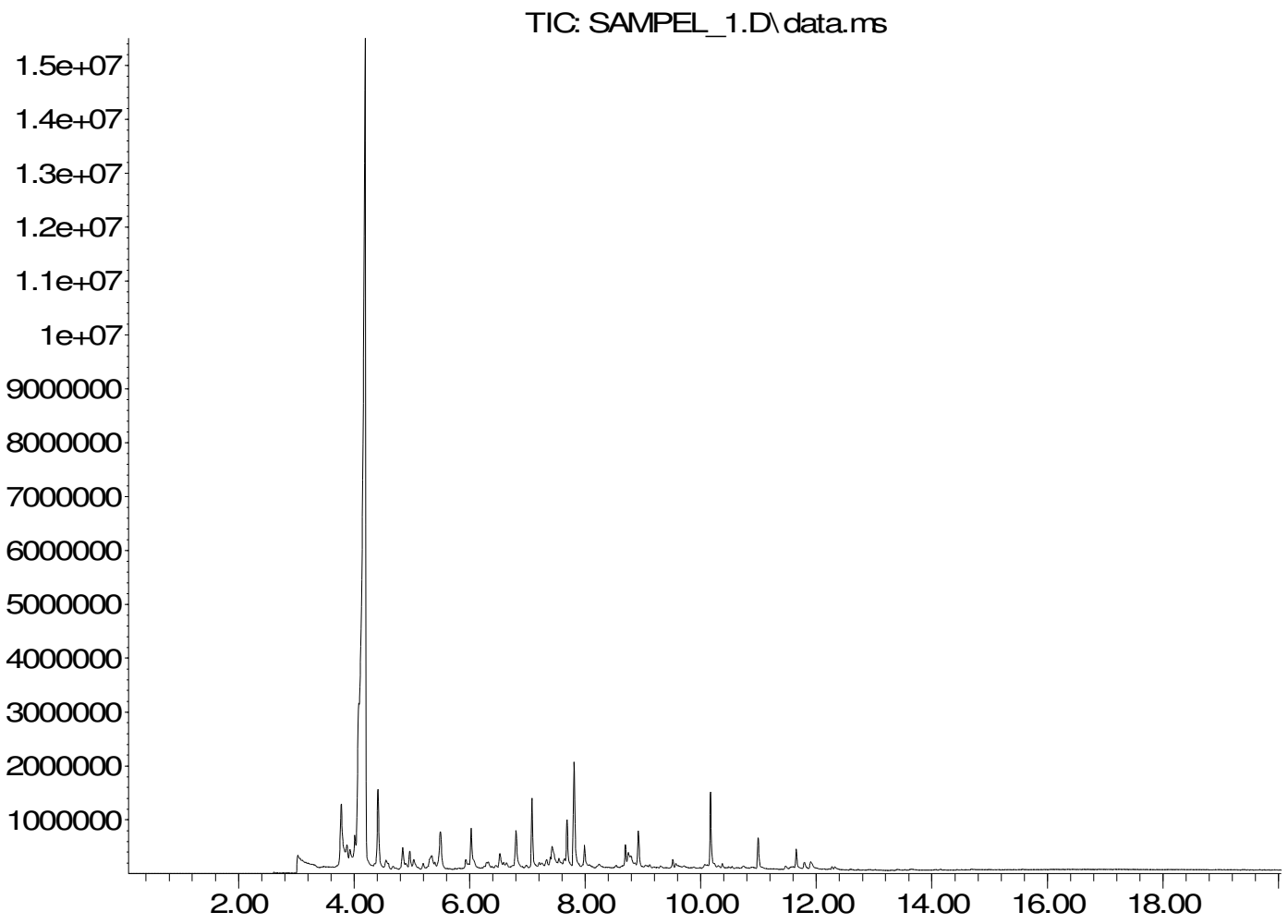

Time $\rightarrow$

Fig.-1: GC chromatogram of Toona sinensis wood vinegar

Table-2: Termiticidal activity of Toona sinensis wood vinegar against Coptotermes curvignathus

\begin{tabular}{l|l|l|l|l|l|l|l}
\hline \multirow{2}{*}{ Sample } & \multicolumn{7}{c}{ Mortality of termite $(\%)^{\text {an }}$ over 1-7 days } \\
\cline { 2 - 8 } & 1 & 2 & 3 & 4 & 5 & 6 & 7 \\
\hline Control & 0 & 0 & 0 & 0 & 0 & 0 & 0 \\
& $\mathrm{~A}$ & $\mathrm{~A}$ & $\mathrm{~A}$ & $\mathrm{~A}$ & $\mathrm{~A}$ & $\mathrm{~A}$ & $\mathrm{~A}$ \\
\hline Wood vinegar [2\%] & 8.48 & 18.18 & 29.7 & 48.48 & 67.88 & 90.91 & 100 \\
& $\mathrm{~A}, \mathrm{~B}$ & $\mathrm{~A}, \mathrm{~B}, \mathrm{C}$ & $\mathrm{C}, \mathrm{D}$ & $\mathrm{E}$ & $\mathrm{F}, \mathrm{G}$ & $\mathrm{H}, \mathrm{I}$ & $\mathrm{I}$ \\
\hline Wood vinegar [4\%] & 19.39 & 43.03 & 60.61 & 78.18 & 94.55 & 100 & 100 \\
& $\mathrm{~A}, \mathrm{~B}, \mathrm{C}$ & $\mathrm{D}, \mathrm{E}$ & $\mathrm{E}, \mathrm{F}$ & $\mathrm{G}, \mathrm{H}, \mathrm{I}$ & $\mathrm{H}, \mathrm{I}$ & $\mathrm{I}$ & $\mathrm{I}$ \\
\hline Wood vinegar [6\%] & 23.64 & 57.58 & 83.64 & 93.33 & 100 & 100 & 100 \\
& $\mathrm{~B}, \mathrm{C}$ & $\mathrm{E}, \mathrm{F}$ & $\mathrm{G}, \mathrm{H}$ & $\mathrm{H}, \mathrm{I}$ & $\mathrm{I}$ & $\mathrm{I}$ & $\mathrm{I}$ \\
\hline Wood vinegar [8\%] & 49.09 & 83.64 & 100 & 100 & 100 & 100 & 100 \\
& $\mathrm{E}$ & $\mathrm{G}, \mathrm{H}, \mathrm{I}$ & $\mathrm{I}$ & $\mathrm{I}$ & $\mathrm{I}$ & $\mathrm{I}$ & $\mathrm{I}$ \\
\hline
\end{tabular}

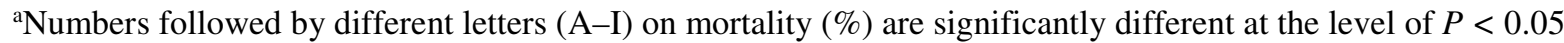
according to Duncan multiple comparison test, $\mathrm{n}=5$ using 33 termites per replicate.

\section{CONCLUSION}

Our results show that the wood vinegar made from Toona sinensis sawdust exhibited strong termiticidal activity. The contents of organic components and acetic acid might be responsible for the termiticidal activity. The $T$. sinensis wood vinegar might be useful for biopesticide in the future application. Future investigations of TS wood vinegar will be focused on anti-wood rotting fungi. 


\section{ACKNOWLEDGEMENT}

The authors would like to acknowledge the financial support of the Ministry of Research, Technology and Directorate General of Higher Education the Republic of Indonesia for a research grant International research collaboration and scientific publication (061/SP2H/LT/DPRM/IV/2017). Thanks to Mohamad Rafi for his assistance in GC-MS. A.J.K. thank head Department of Chemistry to give opportunity as a research assistant at Division of Organic Chemistry.

\section{REFERENCES}

1. M. Verma, S. Sharma, and R. Prasad, International Biodeterioration \& Biodegradation, 63(8), 959 (2009).

2. M. Adfa, A.J. Kusnanda, F. Livandri, R. Rahmad, W. Darwis, M. Efdi, M. Ninomiya, and M. Koketsu, Rasayan Journal of Chemistry, 10(1), 153 (2017).

3. M. Adfa, F. Livandri, N.P. Meita, S. Manaf, M. Ninomiya, I. Gustian, A.M.H. Putranto, R. Supriati, and M. Koketsu, Journal of Asia-Pacific Entomology, 18(1), 475 (2015).

4. T. Nakai, S.N. Kartal, T. Hata, and Y. Imamura, Building and Environment, 42(3), 1236 (2007).

5. L.S. Nerio, J. Olivero-Verbel, and E.E. Stashenko, Journal of Stored Products Research, 45(3), 212 (2009).

6. M. Adfa, Y. Hattori, M. Ninomiya, Y. Funahashi, T. Yoshimura, and M. Koketsu, Natural Product Research, 27(3), 270 (2013).

7. M.B. Isman, Annual Review of Entomology, 51, 45 (2006).

8. K. Tiilikkala, L. Fagernäs, and J. Tiilikkala, The Open Agriculture Journal, 4, 111 (2010).

9. M. Yatagai, M. Nishimoto, K. Hori, T. Ohira, and A. Shibata, Journal of Wood Science, 48(4), 338 (2002).

10. M. Zhai, G. Shi, Y. Wang, G. Mao, D. Wang, and Z. Wang, BioResources, 10(1), 1715 (2015).

11. H.A. Oramahi, and T. Yoshimura, Journal of Wood Science, 59(4), 344 (2013).

12. D.J. Finney, Journal of the Institute of Actuaries, 78(3), 388 (1952).

13. M. Adfa, Y. Hattori, T. Yoshimura, and M. Koketsu, International Biodeterioration \& Biodegradation, 74, 129 (2012).

14. T. Wada, Charcoal Handbook. Bureau of labour and economic affairs, Tokyo, Japan, p. 92 (1997).

15. S. Mathew, and Z.A. Zakaria, Applied Microbiology and Biotechnology, 99(2), 611 (2015).

16. D. Fengel, and G. Wegener, Wood: chemistry, ultrastructure, reactions. Walter de Gruyter, Berlin \& New York (1984).

17. D. Mohan, C.U. Pittman, and P.H. Steele, Energy \& fuels, 20(3), 848 (2006).

18. Y. Akakabe, Y. Tamura, S. Iwamoto, M. Takabayashi, and T. Nyuugaku, Bioscience, Biotechnology, and Biochemistry, 70(11), 2797 (2006).

19. H. Yang, R. Yan, H. Chen, D.H. Lee, and C. Zheng, Fuel, 86(12), 1781 (2007).

20. S.N. Kartal, Y. Imamura, F. Tsuchiya, and K. Ohsato, Bioresource Technology, 95(1), 41 (2004).

[RJC-1866/2017] 